\title{
Whole-Blood Testing for Diagnosis of Acute Zika Virus Infections in Routine Diagnostic Setting
}

\section{Jolanda J.C. Voermans, Suzan D. Pas, ${ }^{1}$ Anne van der Linden, Corine GeurtsvanKessel, Marion Koopmans, Annemiek van der Eijk, Chantal B.E.M. Reusken ${ }^{2}$}

We evaluated the benefit of whole blood versus plasma to detect acute Zika virus infections. Comparison of Zika virus quantitative reverse transcription PCR results in single timepoint whole blood-plasma pairs from 227 patients with suspected Zika virus infection resulted in confirmation of 8 additional patients with Zika virus infection.

Since its emergence in South and Central America in

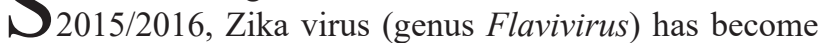
a major public health concern. Zika virus infections are linked to congenital malformations in neonates from mothers infected during pregnancy and to neurologic disorders in adults (1). Thus, the stakes for an accurate diagnosis are high when congenital Zika syndrome might be involved, such as in diagnosis in pregnant women and their partners, because Zika virus infections can be sexually transmitted (1). Diagnostics are based on Zika virus RNA detection, detection of Zika virus-specific antibodies, or both. However, a definitive diagnosis based on serology only is hampered by the existence of a high degree of cross-reactivity between Zika virus and other flaviviruses and their vaccines. In addition, populations with a high background of other flavivirus infections, such as dengue virus, might lack hightiter Zika virus-specific antibody production (also known as original antigenic sin) $(2,3)$. Reverse transcription PCR (RT-PCR) is the most reliable method for confirming Zika virus infections. Viremia in pregnant women can be prolonged, up to 70 days, but more commonly the window of detection for Zika virus RNA in serum or plasma is much shorter (3-14 days after onset of symptoms). The window of detection can be considerably longer for urine and semen, but these specimens are not routinely collected (4-7).

Various studies have suggested that flavivirus genomic RNA might be detectable for longer periods in whole blood than in plasma, thereby expanding the timeframe

Author affiliation: Erasmus Medical Center, Rotterdam, the Netherlands

DOI: https://doi.org/10.3201/eid2507.182000 for viral genome detection to up to 120 days after onset of symptoms $(4,5,8-11)$. Therefore, molecular detection of Zika virus RNA in whole blood instead of plasma might improve Zika virus case confirmation $(12,13)$. In a prospective study, we systematically evaluated the benefit of whole blood versus plasma as the sample of choice to detect acute Zika virus infections in a routine diagnostic setting.

\section{The Study}

We compared Zika virus quantitative reverse transcription PCR (qRT-PCR) results for 249 EDTA-whole blood and EDTA-plasma pairs submitted for laboratory testing from 227 patients with suspected Zika virus infection during July 2016-May 2017. These patients were those with a Zika virus diagnostic request in this period from whom both plasma and whole blood could be collected. In line with previous observations in our laboratory (14), the first day of illness was provided infrequently, in only 29 $(12.8 \%)$ of the 227 patients.

Using a standard EDTA blood collection tube, we aliquoted $600 \mu \mathrm{L}$ of whole blood before the centrifugation step $(10 \mathrm{~min}$ at $2,400 \times g)$ to collect plasma. We stored the samples at $-80^{\circ} \mathrm{C}$ until use. For testing, we spiked the samples with an internal control and extracted total nucleic acids from a $500-\mu \mathrm{L}$ sample in $100 \mu \mathrm{L}$ of eluate using the MagNAPure 96 DNA and Viral NA large volume kit and Viral NA Universal LV 2.0 protocol (Roche, https://www.roche.com), according to the manufacturer's instructions. Extraction was followed by an ISO15189:2012-validated laboratory-developed Zika virus qRT-PCR, as described previously (15). We confirmed all Zika virus RNA-positive samples using a commercial Zika virus qRT-PCR (Altona Diagnostics, http://www.altona-diagnostics.com), as described by the manufacturer.

We detected Zika virus RNA in $31(12.4 \%)$ of 249 whole-blood samples and in 23 (74.2\%) of the 31 corresponding plasma samples. The 31 positive whole-blood samples were collected from 31 individual patients. This comparison indicated that 8 additional Zika virus-positive patients would have been identified if whole blood had been used routinely

${ }^{1}$ Current affiliation: Microvida, Roosendaal, the Netherlands.

${ }^{2}$ Current co-affiliation: Netherlands Centre for Infectious Disease Control, National Institute for Public Health and the Environment, Bilthoven, the Netherlands. 


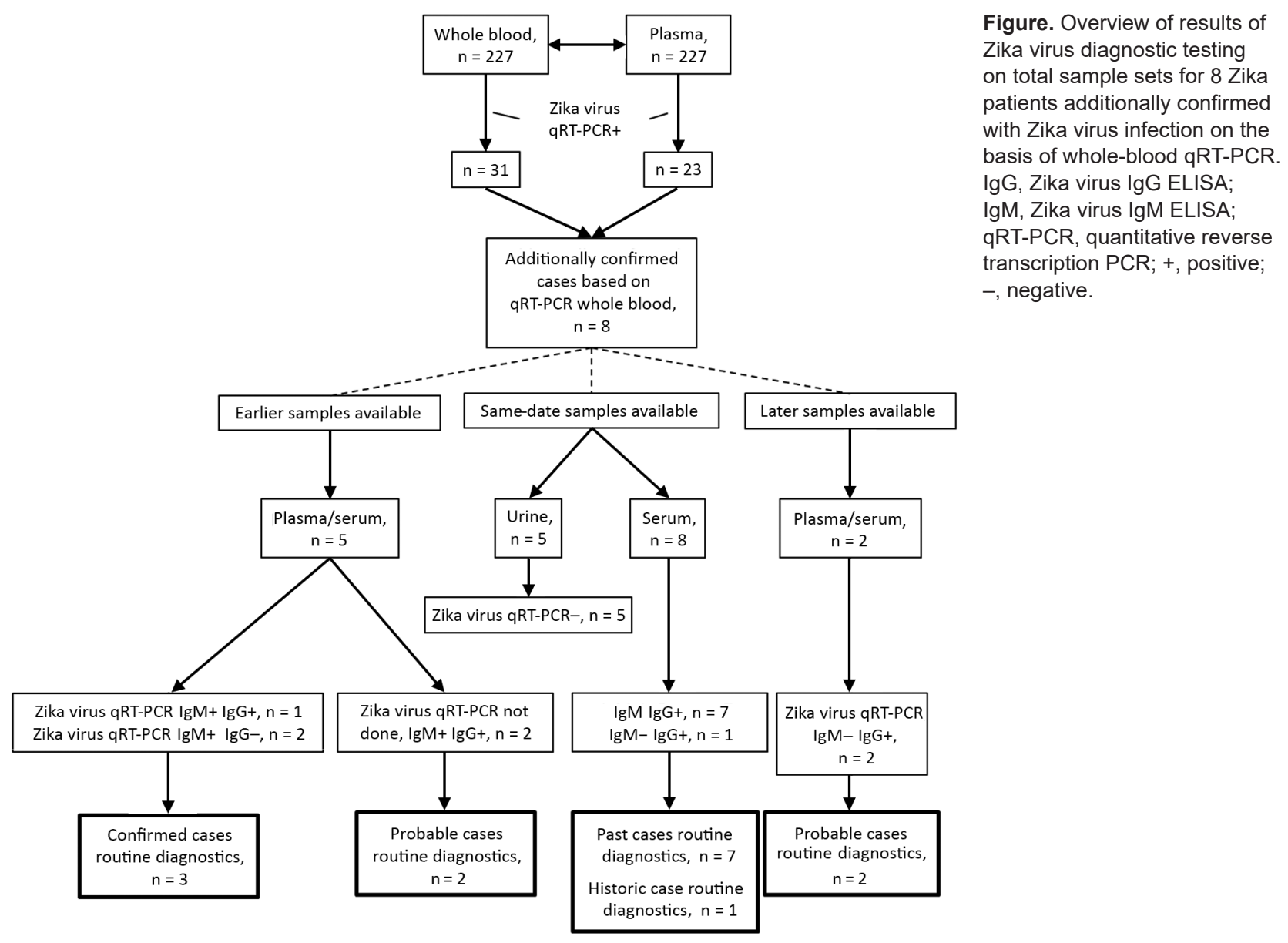

instead of plasma (Figure). This finding represented a 34\% increase in confirmed cases of Zika virus infection.

Standard practice in international guidelines on diagnostic algorithms for Zika virus is to combine molecular testing of plasma with molecular testing of urine, along with serology, to come to an accurate Zika virus diagnosis. However, confirmation of cases based on serology only is usually limited to expert Biosafety Level 3 laboratories being able to perform virus neutralization tests comparing Zika virus titers with titers of other flaviviruses $(12,13)$. In our center, we routinely perform qRT-PCR on plasma and urine while running ELISA IgM/IgG testing in parallel on corresponding serum samples, provided these samples are submitted by treating physicians. Preferably, ELISAs are performed on paired serum samples taken at least 2 weeks apart (acute and convalescent phases) to monitor titer changes. However, these paired samples are not always submitted; for example, in our study cohort a second sample was provided for only 11 (61.1\%) of 18 patients who were seropositive by ELISA and RT-PCR negative in plasma in the initial sample.

To determine whether our routine Zika virus testing algorithm, in which whole blood is not a sample of choice, would have missed the 8 additional identified patients, we evaluated the Zika virus test results of the complete sample set submitted for these patients (Figure). We tested urine and plasma by qRT-PCR as described previously and tested serum by ELISA (Euroimmun, https://www.euroimmun.com) for the presence of Zika virus-specific IgM and $\operatorname{IgG}$, as described by the manufacturer. For 3 of the 8 additional patients, Zika virus infection had already been confirmed on the basis of the presence of Zika virus RNA and IgM in an earlier plasma sample. For the remaining 5 patients, only a status of probable case was achieved without the whole-blood testing (12). Two of these patients had a status of probable infection on the basis of the presence of Zika virus IgM and IgG in an earlier sample, but no PCR was performed. Seven patients had the status of a probable Zika virus infection on the basis of serology performed on a same-date serum sample, and 1 patient had the status of past infection because of the absence of IgM. Two patients had no evidence for a recent Zika virus infection on the basis of a later serum sample that tested negative for RNA IgM and positive for IgG. The semiquantitative Zika virus ELISA did not show significant titer changes between different collection dates (data not shown). 


\section{Conclusions}

Our overall results indicate that, in our routine diagnostic algorithm in the absence of whole-blood testing, the infections of 5 of 227 patients would have been identified as probable Zika virus cases, whereas with whole-blood testing, they would have been identified as confirmed cases on the basis of positive qRT-PCR results. In cases for which only 1 sampling date would have been available, our systematic analysis showed that, of infections in 227 patients, 8 additional Zika virus cases would have been confirmed. Based on these observations, we conclude that individual patient care might benefit from whole-blood testing in a routine diagnostic laboratory setting, thereby possibly reducing the need for more specialized serology (i.e., comparative flavivirus neutralization tests) to confirm cases based on serology. Therefore, we have implemented whole-blood RT-PCR testing for Zika virus diagnostic requests in our routine diagnostic setup. Further studies in larger cohorts, including dengue and chikungunya virus testing, as well to address the often multiplex settings in endemic countries, are needed to demonstrate the general usefulness of our observations.

The work described here was funded by the European Union's Horizon 2020 research and innovation program under project ZIKALLIANCE (grant agreement no. 734548).

\section{About the Author}

Ms. Voermans works in the molecular diagnostics unit of the department of viroscience at Erasmus University Medical Centre, Rotterdam, the Netherlands. She focuses on diagnostic research for emerging viruses of public health importance.

\section{References}

1. Pierson TC, Diamond MS. The emergence of Zika virus and its new clinical syndromes. Nature. 2018;560:573-81. http://dx.doi.org/10.1038/s41586-018-0446-y

2. Charrel RN, Leparc-Goffart I, Pas S, de Lamballerie X, Koopmans M, Reusken C. Background review for diagnostic test development for Zika virus infection. Bull World Health Organ. 2016;94:574-584D. http://dx.doi.org/10.2471/BLT.16.171207

3. Lustig Y, Cotar AI, Ceianu CS, Castilletti C, Zelena H, Burdino E, et al. Lack of Zika virus antibody response in confirmed patients in non-endemic countries. J Clin Virol. 2018;99-100:31-4. http://dx.doi.org/10.1016/j.jcv.2017.12.007

4. Rossini G, Gaibani P, Vocale C, Cagarelli R, Landini MP. Comparison of Zika virus (ZIKV) RNA detection in plasma, whole blood and urine - case series of travel-associated ZIKV infection imported to Italy, 2016. J Infect. 2017;75:242-5. http://dx.doi.org/10.1016/j.jinf.2017.05.021

5. Joguet G, Mansuy JM, Matusali G, Hamdi S, Walschaerts M, Pavili L, et al. Effect of acute Zika virus infection on sperm and virus clearance in body fluids: a prospective observational study. Lancet Infect Dis. 2017;17:1200-8. http://dx.doi.org/10.1016/ S1473-3099(17)30444-9

6. Suy A, Sulleiro E, Rodó C, Vázquez É, Bocanegra C, Molina I, et al. Prolonged Zika virus viremia during pregnancy. N Engl J Med. 2016;375:2611-3. http://dx.doi.org/10.1056/NEJMc1607580

7. Lozier MJ, Rosenberg ES, Doyle K, Adams L, Klein L, Muñoz-Jordan J, et al. Prolonged detection of zika virus nucleic acid among symptomatic pregnant women: a cohort study. Clin Infect Dis. 2018;67:624-7. http://dx.doi.org/10.1093/cid/ciy209

8. Lustig Y, Mendelson E, Paran N, Melamed S, Schwartz E. Detection of Zika virus RNA in whole blood of imported Zika virus disease cases up to 2 months after symptom onset, Israel, December 2015 to April 2016. Euro Surveill. 2016;21:30269. http://dx.doi.org/10.2807/1560-7917.ES.2016.21.26.30269

9. Lustig Y, Mannasse B, Koren R, Katz-Likvornik S, Hindiyeh M, Mandelboim M, et al. Superiority of West Nile virus RNA detection in whole blood for diagnosis of acute infection. J Clin Microbiol. 2016;54:2294-7. http://dx.doi.org/10.1128/JCM.01283-16

10. Huang GKL, Tio SY, Caly L, Nicholson S, Thevarajan I, Papadakis G, et al. Prolonged detection of Japanese encephalitis virus in urine and whole blood in a returned short-term traveler. Open Forum Infect Dis. 2017;4:ofx203. http://dx.doi.org/10.1093/ofid/ofx203

11. El Sahly HM, Gorchakov R, Lai L, Natrajan MS, Patel SM, Atmar RL, et al. Clinical, virologic, and immunologic characteristics of Zika virus infection in a cohort of US patients: prolonged RNA detection in whole blood. Open Forum Infect Dis. 2018;6:ofy352.

12. World Health Organization. Zika virus disease Interim case definitions, 12 February 2016. 2016 [cited 2018 Oct 8]. http://apps.who.int/iris/bitstream/handle/10665/204381/ WHO_ZIKV_SUR_16.1_eng.pdf? sequence $=1$

13. European Commission. Commission implementing decision (EU) 2018/945 of 22 June 2018 on the communicable diseases and related special health issues to be covered by epidemiological surveillance as well as relevant case definitions 2018 [cited 2018 Oct 9]. https://eur-lex.europa.eu/legal-content/EN/TXT/PDF/ ?uri=CELEX:32018D0945\& from $=$ EN\#page $=53$

14. Cleton N, Reusken C, Murk JL, de Jong M, Reimerink J, van der Eijk A, et al. Using routine diagnostic data as a method of surveillance of arboviral infection in travellers: a comparative analysis with a focus on dengue. Travel Med Infect Dis. 2014;12:159-66. http://dx.doi.org/10.1016/j.tmaid.2013.10.015

15. van der Eijk AA, van Genderen PJ, Verdijk RM, Reusken CB, Mögling R, van Kampen JJ, et al. miscarriage associated with Zika virus infection. N Engl J Med. 2016;375:1002-4. http://dx.doi.org/10.1056/NEJMc1605898

Address for correspondence: Chantal B.E.M. Reusken, Erasmus MC, Viroscience, PO Box 2040, 3000CA Rotterdam, the Netherlands; email: c.reusken@erasmusmc.nl 